\title{
A COLLABORATIVE PLATFORM FOR WATER QUALITY MONITORING: SIMILE WEBGIS
}

\author{
J. F. Toro Herrera ${ }^{1, *}$, D. Carrion ${ }^{1}$, M. A. Brovelli ${ }^{1,2}$ \\ ${ }^{1}$ Politecnico di Milano, Dept. of Civil and Environmental Engineering, Politecnico di Milano - Lecco Campus, Via Gaetano previati 1/c, 23900 \\ Lecco, Italy (juanfernando.toro, daniela.carrion, maria.brovelli)@polimi.it \\ ${ }^{2}$ Istituto per il Rilevamento Elettromagnetico dell’Ambiente, CNR-IREA, via Bassini 15, 20133 Milano - maria.brovelli@polimi.it
}

\section{Commission IV, WG IV/4}

KEY WORDS: Decision Support System, Environmental Management, Water Quality, Lake Monitoring, Web Mapping

\begin{abstract}
:
Nowadays, the increasing pressure over water resources is reflecting on the water quality all over the globe. Not surprisingly, local, and regional governments are taking initiatives into tackling this issue. However, the management of water resources requires coordinated management by the stakeholders, especially in cross-border regions, to achieve efficient regulations. Then, the data-sharing for monitoring the water resources is fundamental for the stakeholder participation in the process of knowledge building. This work presents the design and implementation of a collaborative web platform aiming at enhancing these processes applied to share water quality parameters maps produced under the framework of the SIMILE (Integrated monitoring system for knowledge, protection and valorisation of the subalpine lakes and their ecosystems) project. The platform takes advantage of open-source infrastructure and standards. The solution provides two web-based applications devoted to the upload/management (customized GeoNode) of the data and its visualization (WebGIS). The scope of the collaborative platform is to improve the access to information for awareness-building on the water resources in the Insubric area.
\end{abstract}

\section{INTRODUCTION}

Water resources, and thus water quality, have been compromised due to the increasing pressures on the ecosystems such as climate change or anthropic activities (Foley et al., 2005). However, the water management regulations issue faces multiple levels involving different institutions, authorities, and communities to reach efficient outcomes (from policymaking to day-to-day citizen activities). Then, communication, coordination, and data sharing are fundamental to the conservation of water resources.

WebGISs have proven to be an effective tool for water resources management and monitoring, allowing for access and interactive visualization of the water quality indicators and models through the internet, to engage the public and promote awareness (Arias et al., 2017; Brovelli et al, 2019a; Delipetrev et al., 2014; Kulawiak et al., 2010). In this work, we present the design and implementation of a collaborative web platform for sharing remote sensing-based maps (i.e., water quality parameters maps) that have been produced for SIMILE project ("Integrated monitoring system for knowledge, protection and valorisation of the subalpine lakes and their ecosystems"; Brovelli et al., 2019b).

This work focuses on the development of the IT infrastructure to support the management of water resources. Its main goal is to enhance the decision-making process and access to data through a strategic tool for water quality monitoring in the Insubric Area. The platform makes use of open-source infrastructure and open standards. The use of Free and Open Source Software (FOSS) technologies for the platform, guarantee the access to the information without concerns on licenses or purchase constraints. The collaborative platform includes two web-based applications targeting different end-users. The first corresponds to a customised implementation of the GeoNode composition of
FOSS that allows the publication of geospatial data. The customised GeoNode targets the partners involved in the production of the water quality parameters maps. The second is a WebGIS developed for exposing the water quality parameters maps uploaded thanks to the first application. The WebGIS is dedicated both to stakeholders and citizens. Moreover, the collaborative platform looks forward to reducing the technological barriers for sharing and visualizing the water quality parameters monitoring data.

Next, the document presents an outline of the implementation processes of the collaborative platform. Section 2 introduces the datasets hosted by the platform. Section 3 focuses on the IT infrastructure integrated and developed for the platform, along with the integrated functionalities to visualize the data through a WebGIS. At last, section 4 commits to summarize the future direction of the work and possible developments.

\section{WATER QUALITY PARAMETERS DATASETS}

Remote sensing is used for many applications related to water resources assessment such as synoptic soil moisture assessment (Xu et al., 2020), water level monitoring (Crétaux et al., 2011), water demand modelling (Mendoza et al., 2010), groundwater management, flood mapping, and water quality monitoring (De Santi et al., 2019; Gerosa et al.,2021; Luciani et al., 2021; Yigit Avdan et al., 2019). The use of satellite-based products for assessing multiple parameters on water bodies is a less expensive and time-consuming alternative than in-situ surveying on a large scale. For the abovementioned applications, the selection of the sensors poses an important choice depending on the water characteristic to be analysed.

\footnotetext{
* Corresponding author
} 
For SIMILE project, satellite-based maps showing lake water quality parameters for Maggiore, Como, and Lugano lakes, are derived periodically (Luciani et al., 2021), depending on the availability of satellite imagery and on the need of monitoring specific phenomena.

In this case, the satellite monitoring system adopted for the SIMILE project considers the estimation of different water quality parameters based on optical and thermal infrared sensors. The water quality parameters analysed under the framework of the project are the Chlorophyll-a concentration, the Total Suspended Matter and the Lake Surface Water Temperature. Chlorophyll-a (CHL-a) and the Total Suspended Matter (TSM) are monitored with ESA Sentinel-3A/B OLCI whose spectral bands cover the visible spectrum and near-infrared. CHL-a is a measure commonly used as an indicator of the eutrophication level in a water body. Inside an aquatic ecosystem, large concentrations of chlorophyll-a indicate poor water quality, high algal production, and concentration of nutrients. TSM is an indicator of the turbidity of the water body related to the concentration of particulate matter in the ecosystem. The sediment concentration can influence the penetration of light, ecological productivity, and habitat quality, and can harm aquatic life. Another water quality parameter is the Lake Water Surface Temperature (LSWT), processed from the imagery delivered by the NASA Landsat 8 TIRS ("Thermal Infra-red Sensor"). The LSWT has become a widely studied water quality parameter, not only for governing the lake dynamics processes such as sedimentation, concentration of nutrients and the presence of aquatic life, but also on the temporal variability of the temperature evolution due to climate change (Lieberherr et al, 2018).

Then, for project SIMILE, it is of main interest the management and exposure of raster data time series. For this reason, the products are provided with a common naming convention that describes the coordinate reference system, the sensor involved in the acquisition of the imagery, the product typology, and the timestamp of the retrieval of the imagery. An example for the naming convention

“20190415T093540_S3A_CHL_UTM32N". Here, the file name contains information corresponding to the coordinate reference system ("UTM32N"), the sensor involved in the acquisition of the imagery ("S3A", ESA Sentinel3A-OLCI), the product's typology ("CHL", Chlorophyll-a), and the timestamp of the retrieval of the imagery ("20190415T093540", April 15, 2019 at 09:35:40), all separated by an underscore. The provision of a timestamp to the layers gives the possibility for the web client to visualise the layers in time. In addition, the naming convention supported other features such as the styling of the layers and the display of metadata (including the legend for the different datasets). The upload of the datasets with proper metadata stating the corresponding native projection will allow the users to retrieve them in the desired projection.

The frequency of acquisition of the imagery for each of the sensors may vary depending on the cloud coverage for the area of interest. Also, the processing of the estimates of $\mathrm{CHL}$ and TSM can be supported by higher resolution imagery when anomalies are detected (ESA Sentinel-2 A/B MSI, 10-20m spatial resolution imagery). The detailed study on the processing can be found in Luciani et al. (2021) and an example of application of the derived maps is described in Gerosa et al. (2021).
Table 1-3 summarize the currently available datasets in the platform.

\begin{tabular}{|c|c|c|c|}
\hline $\begin{array}{c}\text { Water Quality } \\
\text { Parameters Maps }\end{array}$ & Time span & $\begin{array}{c}\# \\
\text { layers }\end{array}$ & $\begin{array}{l}\text { File } \\
\text { format }\end{array}$ \\
\hline \multirow{2}{*}{ Chlorophyll-a (CHL) } & Jan-11-2019 & \multirow{2}{*}{198} & \multirow{2}{*}{ GeoTIFF } \\
\hline & Dec-26-2020 & & \\
\hline \multirow{2}{*}{$\begin{array}{l}\text { Total Suspended } \\
\text { Matter (TSM) }\end{array}$} & Jan-04-2019 & \multirow{2}{*}{198} & \multirow{2}{*}{ GeoTIFF } \\
\hline & Dec-26-2020 & & \\
\hline \multirow{2}{*}{$\begin{array}{l}\text { Lake Surface Water } \\
\text { Temperature (LSWT) }\end{array}$} & Jan-06-2019 & \multirow{2}{*}{61} & \multirow{2}{*}{ GeoTIFF } \\
\hline & Dec-03-2020 & & \\
\hline
\end{tabular}

Table 1. Datasets currently ingested into the platform

\begin{tabular}{|c|c|c|c|}
\hline $\begin{array}{c}\text { Water Quality } \\
\text { Parameters } \\
\text { maps }\end{array}$ & Projection & $\begin{array}{l}\text { Spatial } \\
\text { resolution }\end{array}$ & $\begin{array}{c}\text { Pre- } \\
\text { processing } \\
\text { Source }\end{array}$ \\
\hline \multirow[t]{2}{*}{ Chlorophyll } & $\begin{array}{c}\text { CH1903+ / } \\
\text { LV95 - Swiss } \\
\text { CH1903+ / } \\
\text { LV95 }\end{array}$ & \multirow[t]{2}{*}{$300 \mathrm{~m}$} & \multirow{2}{*}{$\begin{array}{c}\text { ESA } \\
\text { Sentinel-3 } \\
\text { A/B OLCI }\end{array}$} \\
\hline & $\begin{array}{c}\text { WGS } 84 \text { / } \\
\text { UTM zone } \\
32 \mathrm{~N} \\
\end{array}$ & & \\
\hline \multirow{2}{*}{$\begin{array}{c}\text { Total } \\
\text { Suspended } \\
\text { Matter }\end{array}$} & $\begin{array}{c}\text { CH1903+ / } \\
\text { LV95 - Swiss } \\
\text { CH1903+ / } \\
\text { LV95 }\end{array}$ & \multirow[t]{2}{*}{$300 \mathrm{~m}$} & \multirow{2}{*}{$\begin{array}{c}\text { ESA } \\
\text { Sentinel-3 } \\
\text { A/B OLCI }\end{array}$} \\
\hline & $\begin{array}{c}\text { WGS } 84 \text { / } \\
\text { UTM zone } \\
32 \mathrm{~N} \\
\end{array}$ & & \\
\hline \multirow{2}{*}{$\begin{array}{c}\text { Lake Surface } \\
\text { Water } \\
\text { Temperature }\end{array}$} & $\begin{array}{c}\text { CH1903+ / } \\
\text { LV95 - Swiss } \\
\text { CH1903+ / } \\
\text { LV95 }\end{array}$ & \multirow[t]{2}{*}{$30 \mathrm{~m}$} & \multirow{2}{*}{$\begin{array}{c}\text { NASA } \\
\text { Landsat } 8 \\
\text { TIRS }\end{array}$} \\
\hline & $\begin{array}{lc}\text { WGS } & 84 \quad / \\
\text { UTM } & \text { zone } \\
32 \mathrm{~N} & \end{array}$ & & \\
\hline
\end{tabular}

Table 2. Processed water quality maps currently ingested into the platform

The SIMILE project area of interest covers a cross-border area between Italy and Switzerland. Then, it is imperative to provide the water quality parameters products under cartographic representations that are in use to each of the regions. Table 3 presents the projections considered for each dataset.

\begin{tabular}{|c|c|c|}
\hline Layer Name & Sensor & Typology \\
\hline S3A_CHL_CH & $\begin{array}{c}\text { Sentinel3A } \\
\text { OLCI }\end{array}$ & Chlorophyll-a \\
\hline S3B_CHL_T32 & $\begin{array}{c}\text { Sentinel3B } \\
\text { OLCI }\end{array}$ & Chlorophyll-a \\
\hline S3A_TSM_CH & $\begin{array}{c}\text { Sentinel3A } \\
\text { OLCI }\end{array}$ & Total Suspended Matter \\
\hline S3B_TSM_T32 & $\begin{array}{c}\text { Sentinel3B } \\
\text { OLCI }\end{array}$ & Total Suspended Matter \\
\hline L8_LSWT_CH & $\begin{array}{c}\text { Landsat8 } \\
\text { TIRS }\end{array}$ & $\begin{array}{c}\text { Lake Surface Water } \\
\text { Temperature }\end{array}$ \\
\hline L8_LSWT_T32 & $\begin{array}{c}\text { Landsat8 } \\
\text { TIRS }\end{array}$ & $\begin{array}{c}\text { Lake Surface Water } \\
\text { Temperature }\end{array}$ \\
\hline
\end{tabular}

Table 3 - Processed water quality maps nomenclature 


\section{SYSTEM DESIGN AND IMPLEMENTATION}

\subsection{Design process}

The web collaborative platform design followed two goals concerning the water quality maps. These two goals were: to simplify the process of sharing data and their interactive visualization. The platform integrates two web applications to cover these goals. The architecture for the platform is summarized in Figure 1.First, there is the application dedicated to upload, publish, and manage the water quality maps. The core of this application builds on a GeoNode instance. GeoNode is an open-source Geospatial Content Management System, which facilitates the sharing of geospatial data through a web-based application (https://geonode.org/). GeoNode implements several robust frameworks and software such as Django (https://www.djangoproject.com/), (https://openlayers.org/),

PostgreSQL (https://www.postgresql.org/) (PostGIS; https://postgis.net/), GeoServer (http://geoserver.org/) and PyCSW (Corti et al., 2019). Django web framework provides a user-friendly interface that eases the data sharing process within the platform and the communication with the server. GeoServer supports the backend of the stack and the management of the uploaded files from the GeoNode client-side application. Also, GeoServer grants the possibility to make the data available through Open GeoSpatial Consortium (OGC) standars (https://www.ogc.org/standards). While PyCSW allows handling requests on the catalogue and metadata services. The customized application for the project benefits from some of the components provided by the docker composition for the GeoNode project (https://github.com/GeoNode/geonode/).

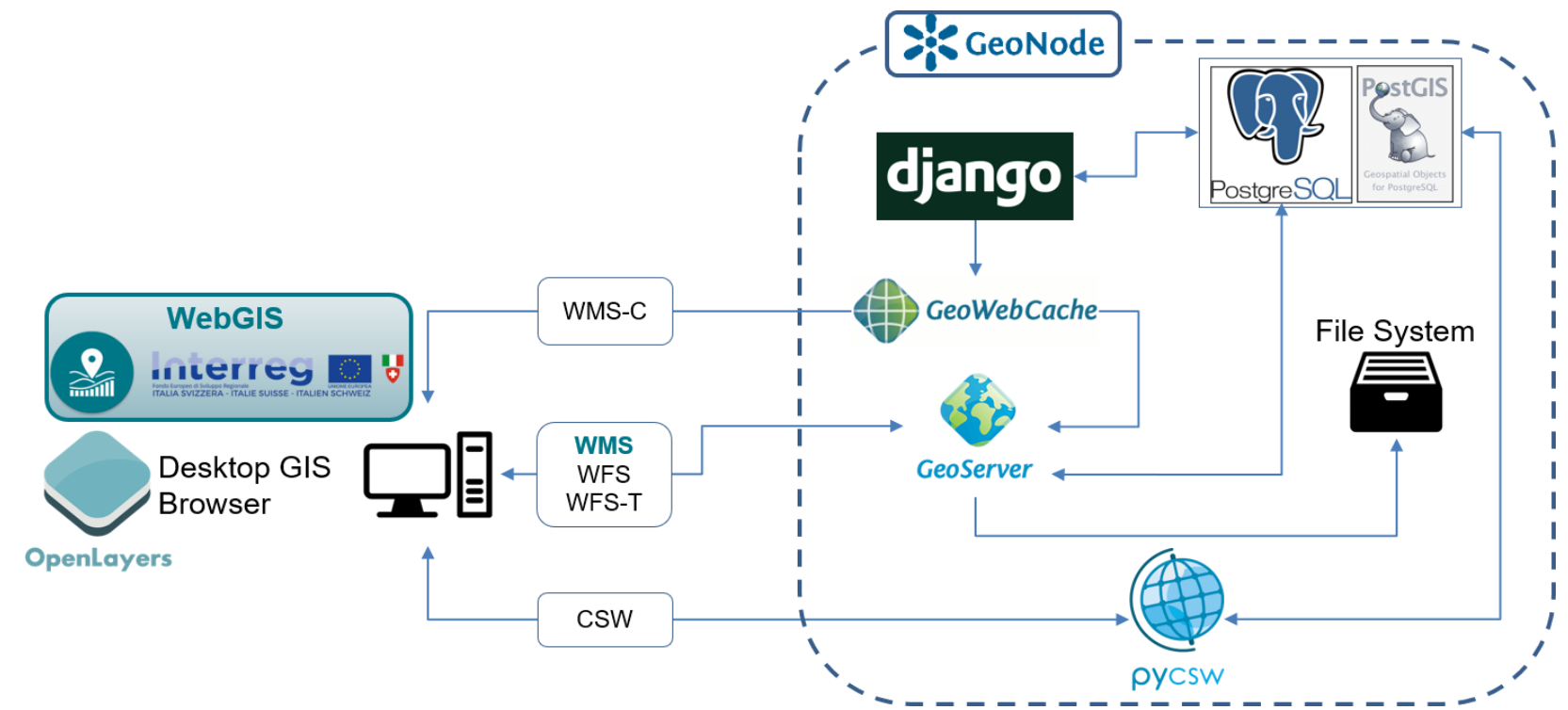

Figure 1. Schematic software architecture for the collaborative web platform

The GeoNode customised application for project SIMILE is dedicated to the producers of the water quality parameters maps. The platform permits the upload of layers (following the stated naming convention) along with additional metadata provided filling a form. Depending on the role of the providers, they will have assigned privileges allowing them to modify or not the datasets. Also, the users can take advantage of introducing the preferred styling for the different water quality map typologies. To add the styles for a map typology, the user must use the same nomenclature of table 3 for the new style definition. Figures 2 and 3 present the main page and the layers page for the customised web-application for SIMILE project.

The second application corresponds to a WebGIS. This application focuses on the visualization of the water quality parameters maps. The WebGIS aims at permitting the exploration and navigability of the datasets available within the server (i.e. the uploaded water quality maps in the GeoNode application). The WebGIS builds upon a node.js runtime environment. Node.js is a javascript runtime environment that allows creating server-side applications using JavaScript. The WebGIS design benefit from the OpenLayers JavaScript web mapping library and the JQuery (https://jquery.com/) JavaScript library. Similarly to the GeoNode platform, the WebGIS node.js application runs in a docker container.

The two applications have been composed independently of one another in separate docker compositions. However, the use of open standards ensures the communication of the two applications. The WebGIS benefits from these standards to request to the server the information about the available layers that have been uploaded into the GeoNode platform (e.g. metadata, image, etc.). 


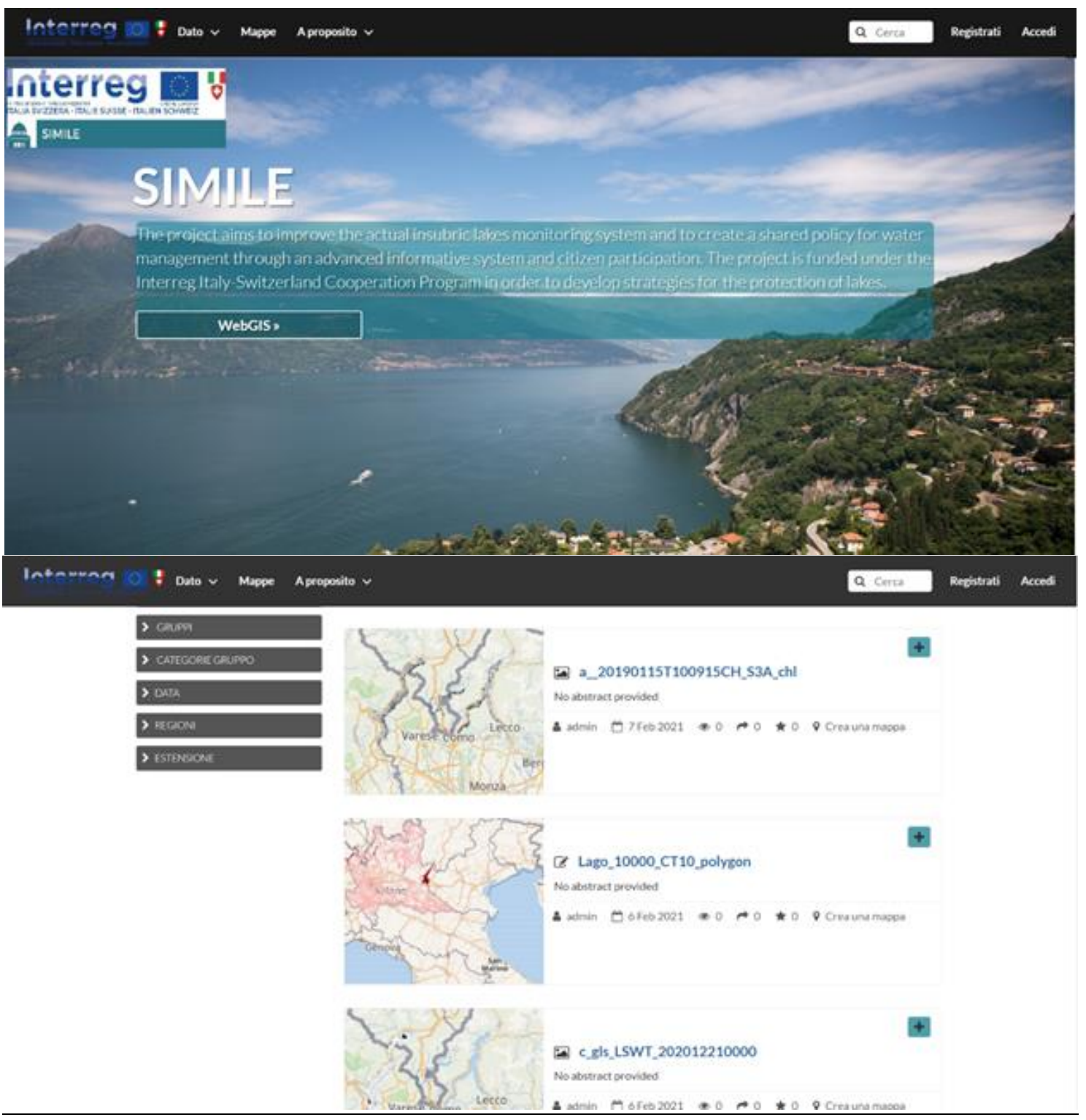

Figure 2. Customized GeoNode plaform user interface. Main page (top) and Layer page (Botton).

The WebGIS aims at being a user-friendly environment for the users to explore the water quality parameters products published on the GeoNode application. The interactive map uses OGC standards, such as Web Mapping Services (WMS, http://www.ogc.org/standards/wms), to display maps published by the map providers. The publication of the datasets through OGC standards are available thanks to GeoServer on the backend of the GeoNode project. The WebGIS includes capabilities that allow users to control the visibility of the layers (i.e. display and opacity), download the datasets, explore the metadata (for a selected layer) and navigate on the map (including zoom in/out functions). The WebGIS retrieves the metadata for each layer in two ways. The first is the one relative to the metadata available from the getCapabilities request from GeoServer (such as the abstract and the style), and the second, regards the information which can be inferred from the naming convention detailed in tables 1-3 (i.e., sensor data, timestamp of image acquisition, map typology and native projection). The parsing of the information of the getCapabilities functionalities will allow the construction of the different time series according to matching layer typologies and the imagery timestamp. Furthermore, the WebGIS dynamically updates the set of layers through the GetCapabilities URL provided by GeoServer.

\subsection{Implementation Process}

SIMILE dedicated WebGIS focuses on the publication of raster datasets of water quality parameters maps, favouring the visualization of the maps as time series. Currently, GeoNode supports the upload of raster datasets in GeoTIFF formats, by taking advantage of the data storage system implemented by GeoServer. Notice that GeoServer provides data formats dedicated to multidimensional raster datasets (e.g. ImageMosaics and NetCDF). However, the direct interaction with the server contemplates a barrier on the data sharing workflow (due to the need for FTP to the server). To overcome the challenge of single image layers, without a timestamp, it was possible to use the timestamps available in the layer's name in order to execute temporal queries. Then, for matching layers typologies, unique dates were extracted to build the group of layers. The groups of layers were produced through the "LayerGroup", that is a collection event for the "Layer" object in the OpenLayers library. 
In this way, it was possible to enable the time series visualization for the water quality parameters in the WebGIS and maintain GeoNode as a suitable tool for easing the publication of raster temporal data.

The WebGIS was developed as a separate application using node.js JavaScript runtime environment. This application operates within a Docker container exposing the WebGIS designed with JavaScript programming language, and OpenLayers and JQuery libraries. The application includes most of the main functionalities, such as a table of contents, overview map, base map selection, zoom in/out, coordinate reference system toolbar, etc (see figure 3). Also, the WebGIS integrates a widget enabling the construction of temporal queries and visualisation of the raster time series (see figure 5). The application benefits of WMS and different capabilities provided by the open specifications implemented within GeoNode. Customised naming conventions of the layers and open specifications allowed to: dynamically update the WebGIS table of contents; customise their visualisation; present their corresponding metadata and download the different products.

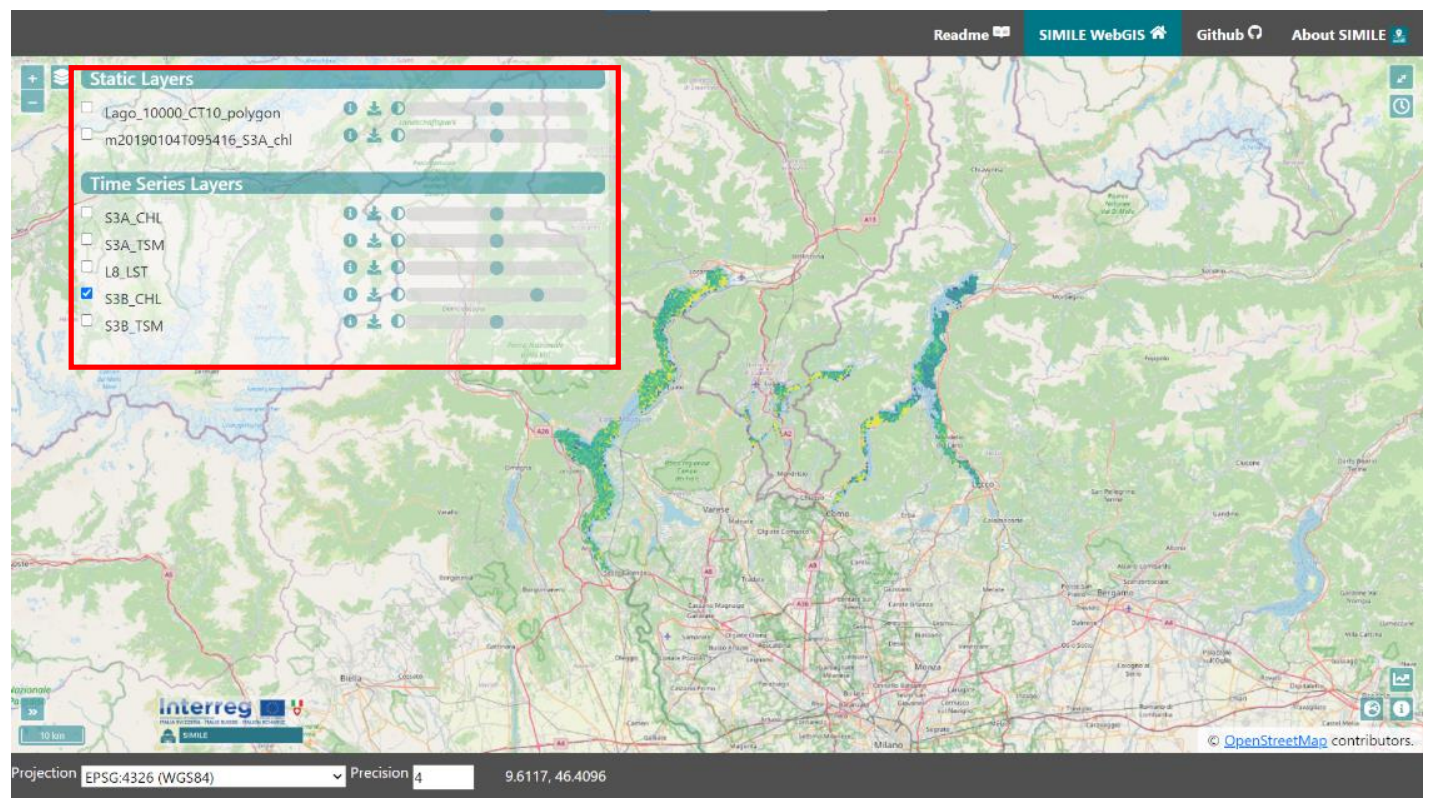

Figure 3. WebGIS user interface, table of contents view

The info button will allow the exploration of the metadata for the corresponding layer in the metadata panel (see figure 4). Similarly to the table of contents, the metadata panel will take advantage of the GetCapabilities request by parsing the metadata of a specific layer. The metadata panel includes information such as an abstract according to the layer's typology, the start/end dates for the first/last in case of a time series, and the symbology to describe the corresponding layer. The symbology, or legend, integrated into the metadata panel makes use of the getLegendGraphic methods implemented by GeoServer.

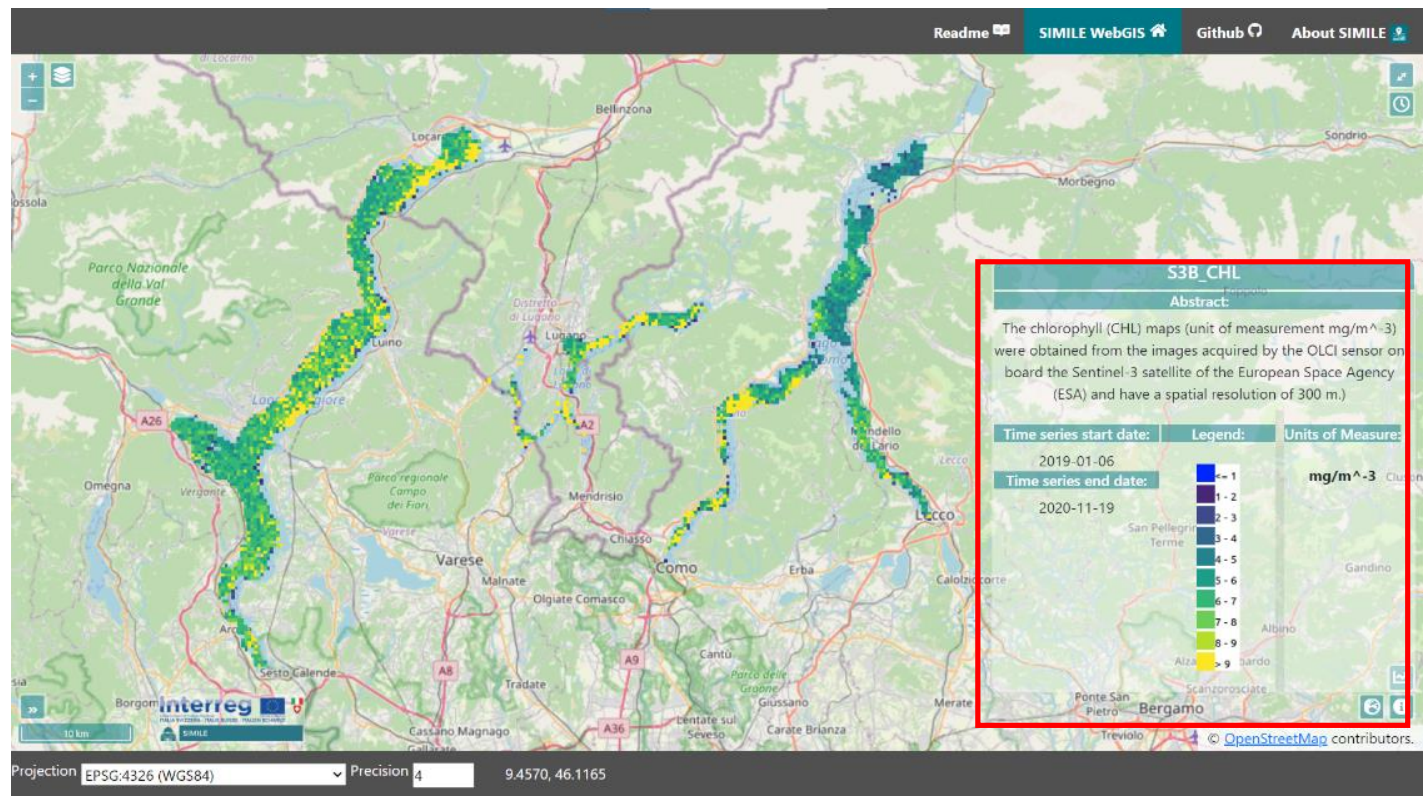

Figure 4. Metadata panel - Example Sentinel3B Chlorophyll-a product 


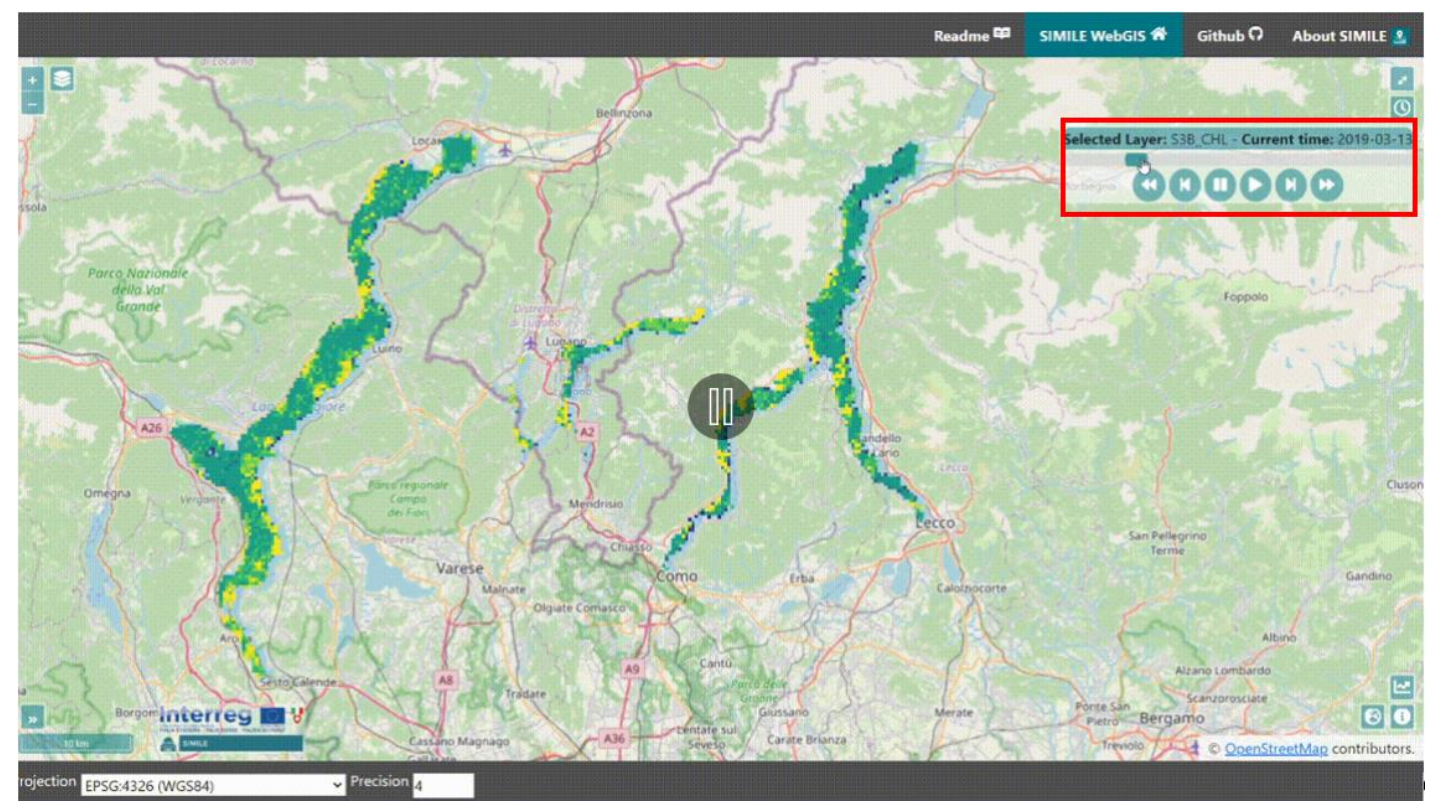

Figure 5. Time widget - Example Sentinel3B Chlorophyll-a product

\section{DISCUSSION}

The implemented collaborative platform provides a strategic tool for the dissemination and monitoring of water quality parameters maps. The platform presents two separate applications devoted to two different target audiences. First, there is the geospatial datasharing platform, directed at the map producers. Here, the users will be able to upload the water quality maps, accompanied by their metadata and style. The uploaded dataset will follow a specific naming convention which opens the doors for the enriched temporal visualization on the second web-based application. On the other hand, the WebGIS provides a userfriendly environment for the visualisation of SIMILE project lake water quality maps produced from satellite imagery granting access to everyone. The application includes different modules such as the table of contents, the metadata panel and the time widget. Then, the users are capable to visualize the different sets of water quality parameters maps by controlling their visibility through the table of contents, explore the characteristics of a specific layer through the metadata panel and, most importantly, displaying the evolution of the different variables in time. The temporal visualization promotes the monitoring of different processes described by the water quality maps. For example, the eutrophication level evolution in a lake characterised by the presence of chlorophyll-a, or the influence of climate change in the variation of the lake surface water temperature over the same seasons on different years. The monitoring and accessibility to the datasets will provide the users' information for assessing the health of the water bodies and their aquatic life. Moreover, the thorough monitoring of the water resources is a must to ensure the livelihood of the communities surrounding the lakes which depend on the consumption of the resource and other anthropic related activities.

The platform aims at becoming a powerful tool for collaboration and publication of water quality parameters monitoring data. These benefits will enable not only the project partners and stakeholders, but also the community of citizens, to have a comprehensive understanding of the scope of the project that is the cross-border management of water resources.

\section{ACKNOWLEDGEMENTS}

The work outlined in this paper is part of project SIMILE (Integrated monitoring system for knowledge, protection and valorisation of the subalpine lakes and their ecosystems) and as such it is financed by the European Commission in the frame of Interreg Italy-Switzerland 2014-2021 program. (Luciani et al., 2021) (De Santi et al., 2019)

\section{REFERENCES}

Arias Muñoz, C., Brovelli, M. A., Kilsedar, C. E., MorenoSanchez, R., \& Oxoli, D. (2017). WEB MAPPING ARCHITECTURES BASED ON OPEN SPECIFICATIONS AND FREE AND OPEN SOURCE SOFTWARE IN THE WATER DOMAIN. ISPRS Annals of Photogrammetry, Remote Sensing and Spatial Information Sciences, IV-2-W4, 23-30. https://doi.org/10.5194/isprs-annals-IV-2-W4-23-2017

Brovelli, M. A., Delipetrev, B., \& Zamboni, G. (2019a). Free and Open Source Tools for Volunteer Geographic Information and Geo-Crowdsourcing. In Geospatial Intelligence: Concepts, Methodologies, Tools, and Applications (pp. 837-862). IGI Global.

Brovelli, M. A., Cannata, M., \& Rogora, M. (2019b). SIMILE, A GEOSPATIAL ENABLER OF THE MONITORING OF SUSTAINABLE DEVELOPMENT GOAL 6 (ENSURE AVAILABILITY AND SUSTAINABILITY OF WATER FOR ALL). ISPRS - International Archives of the Photogrammetry, Remote Sensing and Spatial Information Sciences, XLII-4/W20, 3-10. https://doi.org/10.5194/isprs-archives-XLII-4-W20-32019

Corti, P., Bartoli, F., Fabiani, A., Giovando, C., Kralidis, A. T., \& Tzotsos, A. (2019). GeoNode: An open source framework to build spatial data infrastructures (e27534v1). PeerJ Inc. https://doi.org/10.7287/peerj.preprints.27534v1

Crétaux, J.-F., Arsen, A., Calmant, S., Kouraev, A., Vuglinski, V., Bergé-Nguyen, M., Gennero, M.-C., Nino, F., Abarca Del 
Rio, R., Cazenave, A., \& Maisongrande, P. (2011). SOLS: A lake database to monitor in the Near Real Time water level and storage variations from remote sensing data. Advances in Space Research, 47(9), 1497-1507. Scopus. https://doi.org/10.1016/j.asr.2011.01.004

De Santi, F., Luciani, G., Bresciani, M., Giardino, C., Lovergine, F. P., Pasquariello, G., Vaiciute, D., \& De Carolis, G. (2019). Synergistic Use of Synthetic Aperture Radar and Optical Imagery to Monitor Surface Accumulation of Cyanobacteria in the Curonian Lagoon. Journal of Marine Science and Engineering, 7(12), 461. https://doi.org/10.3390/jmse7120461

Delipetrev, B., Jonoski, A., \& Solomatine, D. P. (2014). Development of a web application for water resources based on open source software. Computers and Geosciences, 62, 35-42. Scopus. https://doi.org/10.1016/j.cageo.2013.09.012

Foley, J. A., DeFries, R., Asner, G. P., Barford, C., Bonan, G., Carpenter, S. R., Chapin, F. S., Coe, M. T., Daily, G. C., Gibbs, H. K., Helkowski, J. H., Holloway, T., Howard, E. A., Kucharik, C. J., Monfreda, C., Patz, J. A., Prentice, I. C., Ramankutty, N., \& Snyder, P. K. (2005). Global Consequences of Land Use. Science, 309(5734), 570-574. https://doi.org/10.1126/science.1111772

GeoNode 3.1 documentation. Retrieved the 29 January 2021, da https://docs.geonode.org/en/master/install/advanced/core/index. html\#install-the-docker-and-docker-compose-packages-on-aubuntu-host

Gerosa, C., Bresciani, Luciani, G., Biraghi, C.A., Carrion, D., Rogora, M., Brovelli, M.A. ZONATION OF SUBALPINE LAKES BASED ON REMOTELY SENSED WATER QUALITY PARAMETERS - Int. Arch. Photogramm. Remote Sens. Spatial Inf. Sci. 2021

Kulawiak, M., Prospathopoulos, A., Perivoliotis, L., Łuba, M., Kioroglou, S., \& Stepnowski, A. (2010). Interactive visualization of marine pollution monitoring and forecasting data via a Webbased GIS. Computers and Geosciences, 36(8), 1069-1080. Scopus. https://doi.org/10.1016/j.cageo.2010.02.008

Lieberherr, G.; Wunderle, S. Lake Surface Water Temperature Derived from 35 Years of AVHRR Sensor Data for European Lakes. Remote Sens. 2018, 10, 990. https://doi.org/10.3390/rs10070990

Luciani, G., Bresciani, M., Biraghi, C. A., Ghirardi, N., Carrion, D., Rogora, M., \& Brovelli, M. A. (2021). Satellite Monitoring system of Subalpine lakes with open source software: The case of SIMILE Project. Baltic Journal of Modern Computing, 9(1). https://doi.org/10.22364/bjmc.2021.9.1.08

Mendoza, M. E., Bocco, G., López-Granados, E., \& Bravo Espinoza, M. (2010). Hydrological implications of land use and land cover change: Spatial analytical approach at regional scale in the closed basin of the Cuitzeo Lake, Michoacan, Mexico. Singapore Journal of Tropical Geography, 31(2), 197-214. Scopus. https://doi.org/10.1111/j.1467-9493.2010.00400.x

Yigit Avdan, Z., Kaplan, G., Goncu, S., \& Avdan, U. (2019). Monitoring the Water Quality of Small Water Bodies Using High-Resolution Remote Sensing Data. ISPRS International Journal of Geo-Information, 8(12), 553. https://doi.org/10.3390/ijgi8120553
Xu, X., Shew, B., Zaman, S., Lee, J., \& Zhi, Y. (2020). Assessment of SMAP and ESA CCI Soil Moisture over the Great Lakes Basin. 4590-4593. Scopus. https://doi.org/10.1109/IGARSS39084.2020.9323638 